\title{
A REALIDADE DAS REDES SOCIAIS: UMA DISCUSSÃO ACERCA DA EDUCAÇÃO MUSICAL NAS COMUNIDADES VIRTUAIS
}

\author{
The reality of social networks: a discussion \\ about music education on virtual \\ communities
}

\author{
La realidad de las redes sociales: una \\ discusión sobre educación musical en \\ comunidades virtuales
}

\author{
DANIEL GOHN \\ Universidade Federal de São Carlos \\ dgohn@ufscar.br
}

\begin{abstract}
Resumo: Este texto propõe uma discussão sobre implicações que as comunidades virtuais trazem para a área da educação musical. São exploradas algumas das mudanças ocorridas na última década, causadas sobretudo pelo desenvolvimento das redes sociais. Como ponto de partida, há questões sobre as possibilidades de contato com novos repertórios, a formação de comunidades com interesses comuns na música e as consequências na formação de professores de música. Em contraposição a perspectivas propícias para a educação musical, são apontadas problemáticas trazidas pelas novas tecnologias, tais como vícios digitais, excesso de informação e dificuldades de concentração causadas por distrações constantes. Observamos uma grande expansão do alcance de redes sociais, conectando bilhões de pessoas ao redor do planeta, assim como a criação de cursos on-line abertos e massivos (MOOCs) que chegam a milhares de indivíduos. Tal quadro demonstra que nossas experiências com música estarão cada vez mais permeadas por interações on-line, forjando um futuro no qual a compreensão de possiveis aspectos nocivos da internet se torna imprescindivel.
\end{abstract}

Palavras-chave: Comunidade virtual. Redes sociais. Educação musical.

\begin{abstract}
This text offers a discussion on the implications that virtual communities bring to the music education field. Some of the changes over the past decade are highlighted, most of them caused by the development of social networks. As a starting point, there are questions about possibilities of getting in touch with new music, the formation of communities with shared interests in music, and consequences in music teachers' training. In opposition to the perspectives that are favorable to music education, problems caused by new technologies such as digital addictions, excess of information and difficulties to focus because of constant distractedness are also discussed. We observed a huge expansion in the purview of social networks, conecting billions of people around the planet, as well as the emergence of massive open online courses (MOOCs) that reach thousands of individuals. Such developments determine that our music experiences will be increasingly permeated by online interactions, forging a future in which the comprehension of possible harmful aspects of the internet become indispensable.
\end{abstract}

Keywords: Virtual community. Social networks. Music education.

Resumen: Este texto propone una discusión sobre las implicaciones que las comunidades virtuales aportan al ámbito de la educación musical. Se exploran algunos de los cambios ocurridos en la última década, provocados principalmente por el desarrollo de las redes sociales. Como punto de partida, se presentan posibilidades de contacto con nuevos repertorios, la formación de comunidades con intereses comunes en la música y las consecuencias para la formación de profesores de música. En contraste con las perspectivas favorables para la educación musical, se señalan problemas provocados por las nuevas tecnologias, como las adicciones digitales, el exceso de información y las dificultades de concentración causados por las distracciones constantes. Hemos visto una gran expansión en el alcance de las redes sociales, conectando a millones de personas en todo el planeta, así como la creación de cursos online abiertos y masivos (MOOCs) que llegan a miles de personas. Tal imagen muestra que nuestras experiencias con la música estarán cada vez más impregnadas de interacciones en línea, forjando un futuro en el que la comprensión de los posibles aspectos perjudiciales de Internet resulta esencial.

Palabras clave: Comunidad virtual. Redes sociales. Educación musical. 
No primeiro semestre de 2008, o artigo "Um breve olhar sobre a música nas comunidades virtuais" foi publicado na Revista da Abem (Gohn, 2008). Naquele momento, as redes eletrônicas estavam em plena expansão e a internet se tornava continuamente mais acessivel para a população brasileira. $O$ que se entendia por "comunidades virtuais" era bem diferente da realidade atual, pois o potencial da interação digital ainda não estava próximo do que surgiria nos anos seguintes, mudando por completo a sociabilidade on-line. A ferramenta mais comum nesse sentido era o Orkut, um site de relacionamentos mantido pela empresa Google, e os computadores desktop ainda eram o meio de acesso à internet mais utilizado. Conforme foi observado na época, o cenário era bastante promissor, com muitas possibilidades para a área da educação musical.

Desde então, aparelhos celulares tornaram o acesso à internet ubíquo, mantendo indivíduos conectados o tempo todo. Os serviços do Orkut foram encerrados em setembro de 2014, ao passo que outras plataformas on-line consolidaram seu alcance, entre as quais destacam-se o Facebook (https:// www.facebook.com), o Instagram (https://www.instagram.com) e o Twitter (https://twitter.com). O termo "comunidades virtuais", popularizado por Rheingold (1993), foi gradualmente sendo substituido por "redes sociais" no cotidiano das pessoas. Turkle (2017) considera que a palavra "comunidade" deveria ter uma definição mais restrita e não seria adequada para retratar redes sociais, embora a própria autora admita que já a usou para descrever muitas situações on-line estudadas por ela. Apesar da constatação de que, nos dias atuais, é "quase uma heresia" sugerir que serviços como o Facebook não se enquadram nessa categoria, Turkle (2017, p. 239, tradução minha) delimita que "comunidades são constituídas por proximidade física, interesses compartilhados, consequências reais e responsabilidades comuns". De forma geral, o que observamos nas relações virtuais tem se afastado dessa definição. Por outro lado, embora reconhecendo que o uso desse termo está envolto em debates acadêmicos, Waldron (2018) sugere que há um certo consenso que grupos de afinidade on-line podem funcionar como comunidades, incluindo aqueles que têm como foco os diferentes gêneros musicais.

Por fim, os termos "comunidade" e "prática" foram associados por Wenger (1998) a um tipo específico de situação, dando origem ao referencial de comunidades de prática. Ao considerar a prática como fonte de coerência para uma comunidade, esse autor apresenta três dimensões, a saber: o engajamento mútuo, o empreendimento conjunto e o repertório compartilhado. Podemos observar tais características em vários cenários on-line com foco na música, em que participantes aglutinam esforços e estabelecem relações ao longo do tempo para realizar ações, negociando significados por meio de conceitos, rotinas, palavras, gestos, ferramentas e símbolos que foram adotados pela comunidade e tornados parte de sua prática. Os empreendimentos engendram e direcionam energia social, envolvendo impulsos e emoções, com uma coordenação de sentidos comparável ao ritmo na música. 
Ritmo não é algo randômico, mas também não é limitador. É parte do dinamismo da música, coordenando o processo pelo qual ela surge. Extraído da performance, se torna fixo, estéril e sem significado, mas na prática musical torna possivel que a música seja interpretada, participativa e compartilhada. É um recurso constitutivo intrínseco da possibilidade da música como experiência compartilhada. Um empreendimento é parte da prática da mesma forma que o ritmo é parte da música (Wenger, 1998, p. 82, tradução minha).

Independentemente das terminologias utilizadas, passados 12 anos da publicação do primeiro artigo sobre a música nas comunidades virtuais na Revista da Abem, o presente texto tem como objetivo atualizar a discussão e reavaliar algumas das premissas que foram inicialmente colocadas. Ainda são válidos os mesmos três pontos de impacto destacados para a educação musical: os diferentes meios de entrar em contato com novas músicas, o surgimento de comunidades em torno de interesses comuns e as novas ferramentas na formação de professores. Tais pontos servirão como sustentáculo para as ideias que se apresentam a seguir.

\section{CONTATO COM NOVAS MÚSICAS}

A crescente facilidade de acesso a músicas na internet reconfigurou por completo nossas formas de contato com novos conteúdos musicais. O desenvolvimento dos arquivos mp3 resultou, primeiramente, em um cenário de generalizada pirataria musical, que "tornou-se, mais para o final dos anos 1990, o que experimentar drogas havia sido para o final dos anos 1960: o desprezo de uma geração inteira tanto pelas normas sociais quanto pelas leis vigentes, quase sem nenhuma consideração das consequências" (Witt, 2015 , p. 88). Embora fosse um ato ilícito, compartilhar arquivos de música pelas redes eletrônicas foi uma prática comum no mundo todo, inicialmente por meio de sistemas peer-to-peer (um para um) como o Napster e depois em BitTorrents nos quais o compartilhamento ocorria de "todos para todos". Aos poucos, serviços legalizados de streaming como Spotify e Deezer popularizaram-se, concretizando a ideia de "música como água", ou seja, como um bem de fácil acesso pelo qual podemos pagar em determinadas situações, mas que em geral será gratuito (Kusek; Leonhard, 2005).

$\mathrm{Na}$ última década, essa foi a grande mudança na mediação tecnológica entre o ouvinte e a música: deixou de ser necessário baixar o arquivo de uma música para escutá-la. Com o pagamento de mensalidades obtêm-se acesso irrestrito a enormes acervos digitais, que podem ser alcançados até mesmo sem custos, ouvindo-se propagandas comerciais e havendo algumas restrições. Além dos serviços específicos de streaming, o YouTube também tornou-se um aglutinador de conteúdos musicais, pois sua finalidade inicial de compartilhamento de vídeos foi expandida com a postagem de gravações, seja de músicas isoladas ou de trabalhos inteiros que originalmente foram produzidos como long plays ou compact discs. Em consequência a esses novos 
meios, aumenta a volatilidade da escuta. Ou seja, ao clicar na tela dos aparelhos digitais, imediatamente começamos a ouvir o que escolhemos e, caso não seja de nosso agrado, podemos decidir por algo diferente. Katz (2004) observou que, no ciberespaço, ouvintes sentem-se mais livres para explorar gêneros musicais desconhecidos, pois não há o risco de desperdiçar tempo ou dinheiro. O mesmo autor descreve uma forma de descobrir novas músicas que chamou de "divergente", a partir de buscas com termos gerais na esperança de resultados amplos e não familiares. Como exemplo, menciona uma busca por "cello" que resultou em territórios musicais que lhe eram previamente desconhecidos, como o quarteto filandês Apocalyptica, que interpreta canções de heavy metal com violoncelos, e a composição de Nick Drake intitulada Cello song.

A serendipidade, esse contato com novas músicas que é fruto do acaso e de acidentes fortuitos, aumentou intensamente com dois fenômenos: as recomendações eletrônicas e as recomendações de pessoas. Nos mais variados serviços digitais, de websites de compras ao streaming, tornou-se comum encontrar a frase "pessoas que gostam disso também gostam de...", seguidas de indicações de produtos ou músicas similares ao que estamos visualizando na tela. No YouTube, além das recomendações na lateral das páginas, há o recurso "reprodução automática", que quando acionado faz com que os vídeos similares toquem sucessivamente, até que seja dado um comando de interrupção. As recomendações de pessoas ocorrem em redes sociais como o Facebook, com um fluxo constante de postagens incluindo vastos espectros de materiais sonoros, no qual dificilmente passamos um dia sem a oportunidade de ouvir novas músicas. Ficamos sabendo o que nossos "amigos" apreciam e até mesmo o que estão ouvindo naquele exato momento. Nos serviços de streaming, há tanto a recomendação eletrônica ("fãs desse artista também curtem...") como recomendações de pessoas, que organizam e tornam públicas suas playlists.

Dessa maneira, se por um lado ampliamos o repertório conhecido de forma exponencial, por outro há o risco da superficialidade na escuta, pois, com um leque de opções tão amplo, concentrar nossa atenção torna-se um desafio. Afinal, "por que escutar um único disco várias vezes, se é possivel ouvir as discografias completas de todos os artistas de que gosto?" (Gohn; Pladevall, 2018, p. 19). A grande disponibilidade de músicas não assegura que estamos de fato desenvolvendo nossa escuta, assim como a grande quantidade de texto na internet e na comunicação das redes sociais não garante um aumento da capacidade de interpretação, raciocínio e reflexão pela leitura. Carr (2014) observou que, com a enxurrada de texto digital em nossos celulares e computadores, as pessoas passam mais tempo lendo. No entanto, é um tipo de leitura rápida, superficial, não linear e de poucas palavras. A leitura profunda e concentrada, no universo digital, está decaindo. O autor mostra evidências de que a mudança do papel para as telas modifica não somente como navegamos a leitura, mas também "o grau de atenção que devotamos a ela e a profundidade de nossa imersão nela" (Carr, 2014, p. 90, tradução minha). Nos anos 1980, o hipertexto foi recebido como um recurso 
educacional de enorme potencial, que poderia fortalecer o pensamento critico dos alunos por fazê-los alternar facilmente entre dois pontos de vista. Em sua reflexão, Carr considera os hyperlinks como ferramentas equivalentes a citações e notas de rodapé, mas que usadas em excesso acabam por desviar o foco do leitor em intermináveis sequências de novas páginas. As ferramentas de busca como o Google também contribuem para a fragmentação da leitura, pois nos acostumamos a isolar nossas respostas do contexto geral. Colocar um livro on-line é desmembrá-lo, sacrificando a coesão do texto e a linearidade de seus argumentos. Se é possivel encontrar a resposta imediata a uma pergunta, muitos acabam não se interessando pela conjuntura que envolve o assunto.

Em suma, além dos aspectos positivos nas facilidades tecnológicas, há possivelmente consequências negativas que são dificeis de perceber e de mensurar. É complexo o quadro de mudanças nas novas gerações em relação à escuta musical. Ainda não temos dados suficientes para compreendê-lo, especialmente ao considerarmos que aqueles nascidos após o desenvolvimento das potencialidades digitais dos celulares e tablets ainda estão chegando à adolescência. ${ }^{1}$ Não sabemos realmente quais serão os impactos futuros da superexposição de tecnologias às crianças. Como compreender um cenário tão recente? Nas comunidades que se formam em ambientes virtuais, as facilidades tecnológicas afetam os participantes de forma geral, o que nos induz a observar e refletir sobre as mudanças específicas na vivência musical dos indivíduos. Tais mudanças são profundas e também demandam tempo para que seus efeitos sejam claramente percebidos e ponderados.

\section{COMUNIDADES FORMADAS EM TORNO DE INTERESSES COMUNS}

As comunidades virtuais que tiveram início na primeira década deste século, inicialmente em bulletin boards e fóruns on-line, ampliaram-se em redes sociais que permeiam o cotidiano de grande parte da população mundial. Em 2019 cerca de 2,2 bilhões de pessoas interagiram diariamente nas principais redes sociais do grupo Facebook (Facebook, Instagram, WhatsApp e Messenger). ${ }^{2}$ Compartilhar imagens, vídeos, ideias e opiniões por esses meios tornou-se frequente e trivial, não apenas entre indivíduos com interesses comuns, mas também entre aqueles com ideias divergentes ou antagônicas. Convivendo com ato tão habitual, é necessário buscar um distanciamento para que os "efeitos colaterais" do uso contínuo dessas redes sejam compreendidos.

Alter (2017) compara o uso desenfreado de aparelhos tecnológicos ao uso de drogas. O autor relata que Sigmund Freud e John Pemberton, o inventor da Coca-Cola, se encantaram com a cocaina e foram usuários entusiastas, percebendo os maleficios disso somente depois de muito tempo. O primeiro

\footnotetext{
1 A primeira versão do iPhone, aparelho produzido pela empresa Apple, surgiu em 2007; o Android, sistema operacional gratuito desenvolvido pela empresa Google, foi lançado no ano seguinte.

2 Dado obtido na página https://newsroom.fb.com/company-info.
} 
afirmava que a droga não apenas dava energia, mas também ajudava em seus problemas de depressão e indigestão, e chegou a escrever cientificamente sobre o assunto, no texto Über Coca, em 1884.

É fácil olhar para trás [...] com um senso de superioridade.
Ensinamos nossas crianças que a cocaina é perigosa e é dificil
acreditar que experts consideravam a droga uma panaceia ape-
nas há um século. Mas talvez nossa sensação de superioridade
seja equivocada. Assim como a cocaina encantou Freud e Pem-
berton, hoje estamos enamorados com a tecnologia. Estamos
dispostos a ignorar os custos de seus beneficios cintilantes: [...]
Facebook e Twitter; Instagram e Snapchat [...]; sites de aposta
on-line; plataformas de vídeo na internet; pontos de streaming
de música [...]; e o surgimento de novas espécies de obsessões,
compulsões e vícios que mal existiam durante o século XX
(Alter, 2017, p. 38-39, tradução minha).

Ou seja, ainda estamos na fase do encantamento com as tecnologias e não percebemos todos os problemas atrelados ao seu uso intenso. Alter apresenta também casos mais recentes que claramente são caracterizados como vício tecnológico, a exemplo de pessoas que passavam dias imersas em jogos eletrônicos, sem pausas para descanso, alimentação, higiene ou contatos com o mundo exterior. Em situações relatadas, os envolvidos só conseguiam se libertar do vício permanecendo internados em instituições específicas para a reabilitação de problemas com tecnologia. Tais extremos são notoriamente casos problemáticos, mas nosso envolvimento corriqueiro com as tecnologias também pode ser questionado. A partir de que ponto pode-se considerar que há excessos? Além disso, como alertado por Turkle (2017, p. 293, tradução minha), "para combater um vício, é preciso eliminar a substância viciante. Mas não vamos 'nos livrar' da internet", ou seja, não iremos proibir o uso de celulares e voltar ao reinado da televisão como elemento aglutinador das famílias.

Tornou-se usual que as redes sociais retenham a atenção de seus usuários durante bastante tempo todos os dias, muitas vezes em situações multitarefas em que a atividade nas redes ocorre paralela a outros trabalhos no domínio digital. O fluxo constante de informações que caracteriza esses ambientes resulta em interações superficiais e atenção reduzida, pois todo e qualquer material é rapidamente substituído por novos conteúdos. Acompanhamos o que nossos "amigos virtuais" estão fazendo a todo instante e recebemos notificações automatizadas dos serviços que "assinamos". Viver conectado no século XXI significa processar avisos que chegam ininterruptamente via sistemas digitais. "Cada um deles é uma distração, mais uma intrusão em nossos pensamentos, mais uma informação que consome um espaço precioso da nossa memória de trabalho" (Carr, 2014, p. 132, tradução minha).

Logo, as redes sociais estão no cerne dos esforços cognitivos que a navegação na internet demanda, o que gera implicações na área educacional. Turkle (2017, p. 242, tradução minha) observou que "educadores foram 
rápidos em exaltar as virtudes de se fazer muitas coisas ao mesmo tempo: era como o futuro queria que pensássemos. Agora sabemos que multitarefas deterioram a qualidade de tudo que tentamos realizar." A autora aponta estudos para embasar esta última afirmação, assim como fizeram Carr (2014) e Alter (2017). Se as redes são tipificadas por interações superficiais e atenção reduzida, assim como foi discutido que a facilidade de acesso à música possivelmente leva a uma escuta superficial, a intensa velocidade nas comunicações virtuais conduz a relações superficiais. Por conseguinte, se na primeira década deste século havia uma perspectiva de construção de comunidades em torno de determinados assuntos, em fóruns específicos e mais restritos, em que aprendizagens aprofundadas eram a norma, nas redes sociais da atualidade as discussões envolvem temas diversos e usualmente ocorrem em ambientes abertos, com postagens visiveis a todos, ${ }^{3}$ nos quais a manutenção do foco e da excelência de qualquer debate é um desafio constante.

Portanto, há que se diferenciar o que Waldron (2018) denomina "comunidades abertas on-line de música" e os serviços de redes sociais como Facebook. No primeiro caso, as ferramentas digitais - fóruns, chats, links do YouTube e de sites correlacionados - possibilitam que visitantes compartilhem conhecimento e tenham discussões acerca do assunto em questão. Pode-se citar como exemplos um website dedicado ao violão, www.violão.org (Scotti, 2016); e outro ao banjo, www.banjohangout.org (Waldron, 2013), em que moderadores e regras fixadas promovem um direcionamento no eixo das atenções, sem o qual provavelmente haveria uma dispersão do tema em tela.

Certamente, os serviços on-line podem ser direcionados de forma a concentrar estudos e servir a propósitos educacionais. Por exemplo, o trabalho de Christopher Cayari (2019) tem demonstrado diversas maneiras de utilizar o potencial do YouTube para fins educacionais, especialmente em projetos de criação musical. Nessa mesma linha, pode-se pensar nos grupos fechados que são criados no Facebook com objetivo intrínseco de promover aprendizagem sobre determinado artista ou gênero musical, quando um mediador poderá garantir que o planejamento básico seja trilhado. Nessas conjunturas, uma rede aberta é configurada para servir primordialmente a um círculo restrito, minimizando as "armadilhas" das distrações on-line e funcionando como um ambiente virtual de aprendizagem.

\section{NOVAS FERRAMENTAS NA FORMAÇÃO DE PROFESSORES}

Na última década, a expansão da educação a distância teve um papel fundamental para a formação de professores no Brasil. Entre 2008 e 2018, segundo dados no Inep (Instituto Nacional de Estudos e Pesquisas Educacionais Anísio Teixeira, 2019), as matrículas de cursos de graduação a distância aumentaram $182,5 \%$, sendo que pela primeira vez o número de alunos

\footnotetext{
3 A generalização se aplica na configuração-padrão da maioria das redes, mas há possibilidades de restrição de acesso a conteúdos em determinados casos.
} 
matriculados em licenciatura nos cursos a distância $(50,2 \%)$ superou o número de alunos matriculados nos cursos presenciais $(49,8 \%)$. Certamente a difusão da internet via celulares e o envolvimento on-line das gerações mais jovens teve um papel crucial no crescimento dessa modalidade de ensino. Diversos estudos já investigaram o uso de redes sociais como parte do ensino superior (Kent; Leaver, 2014), seja como espaço para o compartilhamento de conteúdos ou como oportunidade para "conversas de corredor", ou seja, comunicações que não acontecem no ambiente virtual "oficial" dos cursos (Gohn, 2017). Pesquisadores apresentam opiniões divididas sobre a utilização de Facebook e Twitter como extensões de cursos on-line, pois muitos não consideram que há benefícios significativos e preferem construir blogs ou wikis especificos (Bowman, 2014). De qualquer maneira, as interações digitais de qualquer individuo indubitavelmente produzem implicações em sua formação profissional formal, trazendo ideias, conceitos e opiniões que circulam nas redes sociais.

Além do significativo incremento dos cursos formais de graduação, no campo musical é conspícuo o desenvolvimento de cursos livres na internet, especialmente para o estudo de instrumentos, teoria musical e tecnologias, incluindo um amplo leque de softwares e técnicas de produção musical. Plataformas digitais de MOOC (massive open online courses, ou cursos on-line abertos massivos) como Udacity (www.udacity.org), Coursera (www.coursera. org), edX (www.edx.org) e Udemy (www.udemy.com) concentram conteúdos das mais diversas áreas com números de fato massivos: na Udemy, por exemplo, são 35 milhões de alunos inscritos em 130 mil cursos, oferecidos em mais de 65 linguas. ${ }^{4}$ No entanto, enquanto Udacity, Coursera e edX oferecem cursos de professores de universidades e empresas conhecidas, a Udemy funciona como espaço livre, no qual qualquer individuo pode criar cursos e se tornar um instrutor, sem supervisão de argumentos, ideias e materiais utilizados. De forma similar ao que o YouTube realizou com a postagem de vídeos, a Udemy criou um terreno amplo para o compartilhamento de conteúdos educacionais. Tal situação gera questionamentos sobre a qualidade dos cursos, assim como são questionáveis os sistemas de autoavaliação ou de peer assessment adotados pelo Coursera, em que a avaliação da aprendizagem é realizada por colegas, possivelmente inexperientes e inaptos (Admiraal; Huisman; Van de Ven, 2014).

A concepção básica do MOOC nas plataformas citadas acima é de palestras gravadas e, "embora os professores possam ser notáveis, a pedagogia está associada a um modelo ultrapassado de 'cabeças falantes' e questionários de múltipla escolha, na realidade uma pedagogia desatualizada por meio de um veículo atual" (Bowman, 2014, p. 208). Para a formação do que estamos chamando de comunidade, são oferecidas ferramentas de comunicação entre alunos e professores, usualmente com fóruns escritos, mas a capacidade desse sistema para fomentar interações interpessoais tem sido

\footnotetext{
4 Dados do segundo semestre de 2020, obtidos no endereço eletrônico https://about.udemy.com.
} 
continuamente contestada (Poquet; Kovanović; De Vries; Hennis; Joksimović; Gašević; Dawson, 2018). Em outros casos, especialmente nas situações que não são consideradas de "ensino massivo", a possibilidade de trocas frutíferas entre os envolvidos pode ser maior. Por exemplo, no curso on-line do baterista Dave Weckl (www.daveweckl.com), desenvolvido na plataforma Teachable (teachable.com), os alunos têm acesso a grupos fechados no Facebook, onde postam vídeos de suas performances e resolvem dúvidas. Forma-se uma comunidade de prática, na concepção de Wenger (1998): há um foco bem definido no engajamento dos participantes, que se lançam em um empreendimento conjunto (aprendizagem do instrumento musical) e compartilham o repertório de conceitos e propostas do professor responsável. Nessa comunidade os objetivos das interações são bem delineados e os materiais são restritos aos membros, ainda que haja uma linha tênue com as redes sociais abertas dos participantes, nas quais há espaço para todo tipo de postagens pessoais ou políticas.

A questão principal passa a ser a combinação entre o potencial de comunicação das redes on-line, que abrem conexões para o universo digital de informações e pessoas dispersas ao redor do globo, com o foco em um objetivo comum, bem desenhado e coeso para um grupo. Nesse sentido, as potencialidades da internet possivelmente são também armadilhas, pois provocam constantes distrações numa "cacofonia de estímulos que causa curtos-circuitos tanto nos pensamentos conscientes como nos inconscientes, impedindo nossas mentes de pensar produtivamente ou criativamente" (Carr, 2014, p. 119, tradução minha). Ou seja, ao estudar por meios eletrônicos e de forma coletiva, enfrentamos desafios para dosar os estímulos e dimensionar o escopo de nossos interesses.

Por outro lado, qualquer que seja o modelo de ensino-aprendizagem, as interações possiveis entre mestres e aprendizes nos ambientes on-line apresentam-se como um diferencial em relação aos ambientes puramente off-line. Estratégias para o uso de recursos abertos por meio de ferramentas on-line como blogs, podcasts e wikis têm sido desenvolvidas há mais de uma década para canalizar o potencial de aprendizagem colaborativa (Ruthmann, 2007). $\mathrm{Na}$ associação a comunidades de prática, é possivel "encontrar seus pares" e dividir problemas, anseios e conquistas. Nos anos de formação inicial de professores, dificilmente há tempo para aprofundar todas as áreas envolvidas na educação musical, como a prática de instrumentos musicais, estudos pedagógicos e recursos tecnológicos. Contribuindo para essa área, as plataformas on-line servem como fontes para educação continuada, possibilitando aperfeiçoamentos ao longo da vida e atualizando professores sobre a realidade de seus alunos. Seja em cursos massivos, grupos menores ou conteúdos dispersos na internet, observamos uma ampla difusão de informações e conhecimentos, que eventualmente são explorados e esmiuçados em comunidades virtuais. Portanto, há uma relevância considerável das redes eletrônicas na formação de professores de música, ampliando o campo de suas aprendizagens em diversas esferas da educação musical. 


\section{CONSIDERAÇÕES FINAIS}

A publicação do artigo "Um breve olhar sobre a música nas comunidades virtuais" ocorreu durante um período de expansão das primeiras redes sociais, o que possibilitou a formação de comunidades em torno da música, seja para compartilhar o prazer de sua fruição ou para aprender sobre ela. Desde então, ficou evidente a consolidação da internet como agente de transformação global, inevitável e ubíquo, permeando as relações na educação musical. As plataformas mudaram e, ao passo que o Orkut desapareceu e surgiram o Facebook, o Instagram e o Twitter, outras como o MySpace (myspace.com) e o SoundCloud (soundcloud.com) continuam, mas com menor relevância no cenário das redes sociais. Portanto, é razoável a expectativa de que outras plataformas despontem no futuro próximo, com novas ferramentas que irão moldar nossas interações.

É importante frisar que essas observações ocorrem no contexto das realidades socioeconômicas que possibilitam um envolvimento com as tecnologias digitais. No Brasil e em muitos países, há regiões que enfrentam a fome e a miséria, onde outras prioridades dominam os esforços de grande parte da população, sem acesso aos recursos que são mencionados neste artigo. A literatura aqui citada, em sua maioria internacional, de forma geral não considera essa questão e coloca as redes sociais como universais e onipresentes. Todavia, com a constatação de que os celulares estão continuamente envolvendo mais pessoas no ambiente digital, chegando a consideráveis contingentes da população brasileira, a discussão torna-se pertinente e relevante.

Dessa forma, é certo que a música continuará sendo compartilhada e objeto de discussões nas comunidades virtuais. Com a integração de diferentes espaços on-line, como tem acontecido entre os serviços de streaming e as redes sociais, teremos cada vez maiores facilidades no acesso a conteúdos musicais. Espera-se que as oportunidades de aprendizagem sejam aproveitadas e que a maior circulação de material sonoro tenha resultados positivos na área da educação musical. O campo para pesquisas científicas será vasto e bastante rico nesse aspecto, repleto de quadros passiveis de investigação. Para quais caminhos as interações on-line nos levarão nas próximas décadas?

Teremos que acompanhar também como as tecnologias digitais irão modificar a relação de professores de música com seus alunos. Além disso, não importa a modalidade (presencial ou a distância) e o contexto (formal, não formal ou informal, quaisquer que sejam as definições) da formação inicial do professor de música, é certo que informações advindas das redes sociais estarão presentes. O simples fato de interagir com um círculo de "amigos" ampliado tecnologicamente cria possibilidades impensáveis sem a internet. Ocorrem reformulações de opinião, absorção de informações e transformações de concepções de mundo. Mas, ainda mais importante, os professores poderão buscar comunidades para sua formação continuada, seja em grupos nas redes sociais ou em websites dedicados especificamente para educação musical. Em situações de ensino massivo, ainda que não aconteçam 
interações significativas entre os participantes, há que se reconhecer o incentivo de saber que milhares de pessoas estão passando pelo mesmo processo de estudos e enfrentando os mesmos desafios.

Finalmente, chegamos ao entendimento de que por um lado as comunidades virtuais abrem trilhas promissoras, mas por outro as tecnologias oferecem riscos: vícios digitais, excesso de informação e distrações constantes, por exemplo. Se realmente estamos ainda na "fase do encantamento", é provável que muitos desses problemas, ainda que percebidos, sejam relevados. Afinal, as vantagens advindas da internet são tamanhas que seus efeitos colaterais muitas vezes são anistiados. Nas relações com as tecnologias em geral, e nas comunidades virtuais em particular, é preciso avaliar os pontos positivos e negativos, identificando condutas contraproducentes, buscando equilibrio e evitando excessos danosos. Somente dessa forma poderemos almejar experiências significativas e vivências prazerosas, com boas perspectivas para a educação musical e sem concessões adversas em contrapartida.

\section{REFERENCIAS}

ADMIRAAL, Wilfried.; HUISMAN, Bart.; VAN DE VEN, Maarten. Self- and peer assessment in Massive Open Online Courses. International Journal of Higher Education, Richmond Hill, v. 3, n. 3, 2014, p. 119-128.

ALTER, Adam. Irresistible: the rise of addictive technology and the business of keeping us hooked. New York: Penguin Press, 2017.

BOWMAN, Judith. Online learning in music: foundations, frameworks, and practices. New York: Oxford University Press, 2014.

CARR, Nicholas G. The glass cage: how our computers are changing us. New York: W.W. Norton \& Company, 2014.

CAYARI, Christopher. Facilitating music video projects in the classroom: from YouTube to musical playground. In: MORI, Zack.; POWELL, Bryan.; SMITH, Gareth Dylan (ed.). The Bloomsbury handbook of popular music education: perspectives and practices. London: Bloomsbury Academic, 2019. p. 219-226.

GOHN, Daniel. Um breve olhar sobre as comunidades virtuais de música. Revista da Abem, n. 19, p. 113-119, mar. 2008.

A segunda fase da vivência tecnológica. In: SANTIAGO, Glauber. Usos de recursos tecnológicos na educação musical. São Carlos: EDUFSCar, 2017. p. 23-36.

GOHN, Daniel; PLADEVALL, Jayme. No mundo da bateria: conceitos, ideias e composições. São Paulo: Editora Som, 2018. 
INSTITUTO NACIONAL DE ESTUDOS E PESQUISAS EDUCACIONAIS ANÍSIO TEIXEIRA. Censo da educação superior 2018: notas estatísticas. Brasília: Inep, 2019.

KATZ, Mark. Capturing sound: how technology has changed music. Berkeley: University of California Press, 2004.

KENT, Mike; LEAVER, Tama. An education in Facebook?: higher education and the world's largest social network. New York: Routledge, 2014.

KUSEK, David; LEONHARD, Gerd. The future of music: manifesto for the digital music revolution. Boston: Berklee Press, 2005.

POQUET, Oleksandra; KOVANOVIĆ, Vitomir; DE VRIES, Pieter; HENNIS, Thieme; JOKSIMOVIĆ, Srećko.; GAŠEVIĆ, Dragan; DAWSON, Shane.

Social presence in massive open online courses. The International Review of Research in Open and Distributed Learning, Athabasca, v. 19, n. 3, p. 43-68, July 2018.

RHEINGOLD, Howard. The virtual community: homesteading on the electronic frontier. Reading: Addison-Wesley, 1993.

RUTHMANN, S. Alex. Strategies for supporting music learning through online collaborative technologies. In: FINNEY, John; BURNARD, Pamela. (ed.). Music education with digital technology. New York: Continuum, 2007. p. 131-141.

SCOTTI, Adelson. Violão no espaço virtual: construindo saberes. Curitiba: Prismas, 2016.

TURKLE, Sherry. Alone together: why we expect more from technology and less from each other. 3rd ed. New York: Basic Books, 2017.

WALDRON, Janice. User-generated content, YouTube and participatory culture on the web: music learning and teaching in two contrasting online communities. Music Education Research, [s. l.], v. 15, n. 3, 2013, p. 257-274. Online music communities and social media. In: BARTLEET, BrydieLeigh.; HIGGINS, Lee. Oxford handbook of community music. New York: Oxford University Press, 2018. p. 109-130.

WENGER, Étienne. Communities of practice: learning, meaning, and identity. New York: Cambridge University Press, 1998.

WITT, Stephen. Como a música ficou grátis: o fim de uma indústria, a virada do século e o paciente zero da pirataria. Rio de Janeiro: Intrínseca, 2015. 
Daniel Gohn é professor do curso de Licenciatura em Educação Musical da Universidade Federal de São Carlos (UFSCar). Mestre e doutor pela Escola de Comunicações e Artes da Universidade de São Paulo (ECA/USP) e bacharel em Música Popular pela Universidade Estadual de Campinas (Unicamp), é autor de No mundo da bateria: conceitos, ideias e composições, em parceria com Jayme Pladevall (Editora Som, 2018), Caderno de percussão Yamaha (Ricordi, 2014), Educação musical a distância: abordagens e experiências (Cortez, 2011), Tecnologias digitais para educação musical (EdUFSCar, 2010) e Autoaprendizagem musical: alternativas tecnológicas (Annablume, 2003). Seus principais interesses de pesquisa incluem o uso de tecnologias na educação musical e processos de ensino e aprendizagem de instrumentos de percussão. https://orcid.org/0000-0002-3940-1229 